\title{
Funding Mechanism
}

National Cancer Institute

\section{Source}

National Cancer Institute. Funding Mechanism. NCI Thesaurus. Code C20020.

The type of award an agency makes to support a program and within which it

incorporates the terms and conditions for expending the funds and performing the work. 